\title{
THE ANALYSIS OF ADAPTATION IN A PLANT-BREEDING PROGRAMME
}

\author{
By K. W. FINLAY* and G, N. WILKINSON†
}

[Manuscript received January 23, 1963]

Summary

The adaptation of barley varieties was studied by the use of grain yields of a randomly chosen group of 277 varieties from a world collection, grown in replicated trials for several seasons at three sites in South Australia. For cach variety a linear regression of yield on the mean yield of all varieties for each site and season was computed to measure variety adaptation. In these calculations the basic yields were measured on a logarithmic scalc, as it was found that a high degree of linearity was thereby induced. The mean yield of all varieties for each site and season provided a quanticative grading of the environments; and from the analysis described, varieties specifically adapted to good or poor seasons and those showing general adaptability may be identified.

The study of the adaptation of the whole population of varieties was facilitated by the use of a two-dimensional plot (scatter diagram), with mean yield and regression coefficient as coordinates for each variety. Though wide variation was evident in both mean yield and sensitivity to environment as characterized by the regression coefficient, the variation in sensitivity was proportionately less among varicties with higher mean yield, and the varieties with highest mean yicld exhibited, within very narrow limits (regression coefficients close to 0.8 ), a similar degree of adaptation to all environments over the wide range, especially of seasonal conditions, typical of the South Australian cereal belt.

Varieties from particular geographic regions of the world showed a similarity in type of adaptation, which provides a useful basis for plant introduction.

Phenotypic stability and physiological and morphological characteristics of groups of varieties with specific or general adaptability are discussed in relation to plant introduction and breeding.

\section{INTRODUCTION}

The ability of some crop varieties to perform well over a wide range of environmental conditions has leng been appreciated by the agronomist and plant breeder.

In the cereal belts of southern Australia this general adaptability has proved to be of particular importance, because edaphic variation between localities and the seasonal variation in any one locality are very great. Furthermore, some of these environmental conditions are changing. Soil fertility has increased appreciably in many cereal areas owing to the increasing use of clover and medic pastures in the rotation, while the boundaries of the cereal areas are changing as wheat is extended to regions of higher rainfall and newly developed fertility, and barley moves into "marginal wheat country".

Frankel (1958) pointed out tnat in meeting the demands for varieties better adapted to changing conditions, the plant breeder is faced with the choice of breeding

-Waite Agricultural Research Institute, University of Adelaide.

TDivision of Mathematical Statistics, C.S.I.R.O., Adelaide, and Waite Agricultural Research Institute, University of Adelaide. 
either for closely defined ecological conditions or for more extensive conditions which include a considerable range of environments. Clearly the latter approach requires the development of varieties possessing general adaptability; the alternative approach of breeding varieties adapted to closely defined ecological conditions may be satisfactory for horticultural crops growing in environments, modified by the addition of water and nutrients, but has serious limitations for dryland field crops. Even in a uniform edaphic environment a considerable degree of general adaptability will be important, because of the marked fluctuation of climatic conditions from season to season.

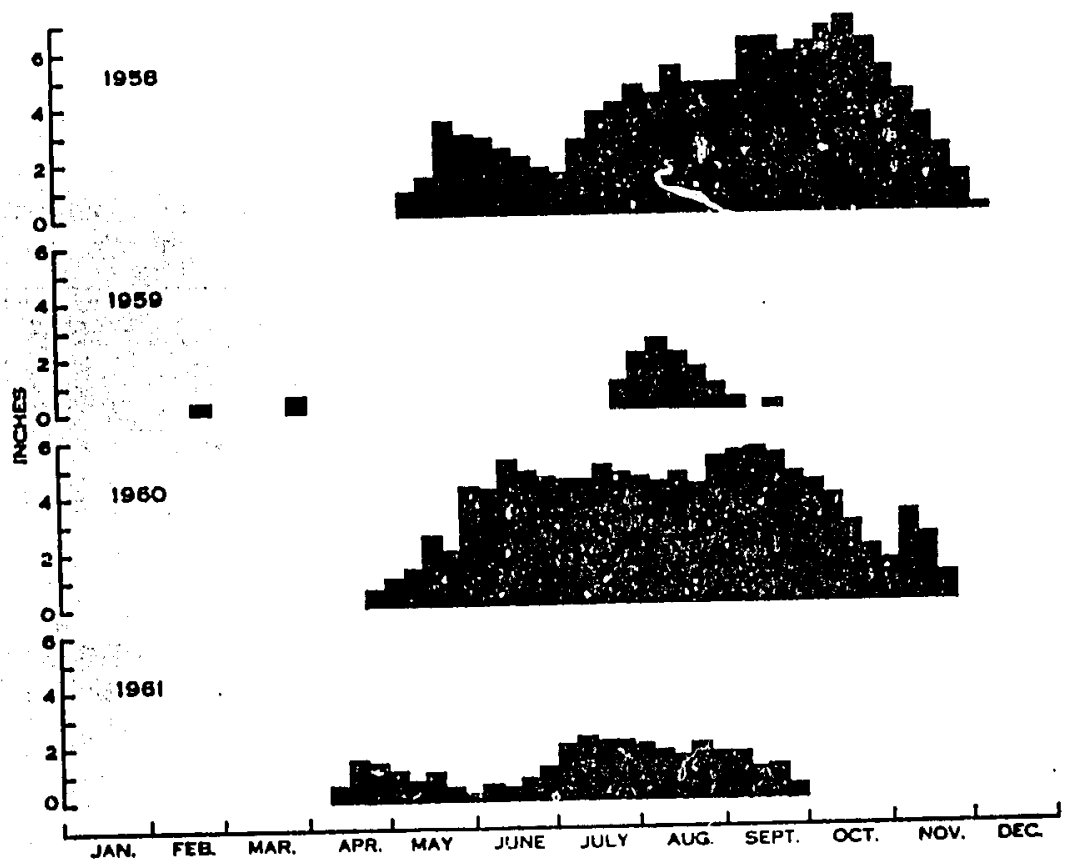

Fig. 1.-Yearly differences in soil moisture balance in the vicinity of the Waite Institute, based on rainfall less an estimated evapotranspiration. Information for this figure was supplied by J. A. Prescott.

This is especially true in southern Australia. Rainfall, and thus soil moisture, is the most important climatic factor varying from season to season. Prescott (personal communication, 1962) has developed a technique which illustrates this point well. He estimates the soil moisture storage balance based on the difference between weekly rainfall and estimated evapotranspiration $\left(1 \cdot 2 E^{0.75}\right)$ in inches. The black areas in Figure 1 give an estimate of the amount of water in the soil for plant growth in the vicinity of the Waite Agricultural Research Institute in 1958-1961. Sites throughout the cereal belts of southern Australia would show a similar range of patterns; the wide range of seasonal differences is evident.

Although plant breeders have been aware of important genotypic differences in adaptability, they have been unable to exploit them fully in breeding programmes. This has been due largely to problems of defining and measuring either adaptability 
itself or the complexities of natural environments. Various workers (e.g. Immer, Hayes, and Powers (1934), Salmon (1951), Horner and Frey (1957), and Sandison and Bartlett (1958) have discussed some of the methods and problems of comparing varietal performance in several environments for several years. In their work, the variety $\times$ location or variety $\times$ season interactions were the basic measures of adaptability. Although these are useful parameters they fail to give an adequate account of the dynamic response of varieties to different environments. The technique lacks precision, and is difficult to use when large numbers of genotypes are being tested, e.g. in a plant introduction programme, or in testing a large population of selections in a breeding programme; a great array of changed rankings of varieties from site to site, and season to season, confuse the interpretation of the data.

In a related field, research into phenotypic stability (developmental homeostasis) carried out by Lerner (1954), Lewis (1954, 1955), Dobzhansky and coworkers (1955a, 1955b), Williams (1960), Griffing and Langridge (1961), and others, has provided considerable detailed and fundamental knowledge about the nature and significance of adaptation in both animals and plants. These studies, mostly carried out under controlled environment conditions, provide fundamental information about phenotypic stability, heterosis, and response to environmental change. One result of the continued development of fundamental concspts from this type of research has been to emphasize the considerable gap between the laboratory and the field worker. In spite of countless varicty trials in the field, over a wide range of enlvironments, few basic principles have been evolved from field studies of adaptability.

In an attempt to bridge this gap, a simple, dynamic interpretation of varietal adaptation to natural environments has been developed for use in a plant-breeding programme at the Waite Institute, and is presented in this study. It provides a basis for the formulation of broad biological concepts of value to the agronomist and plant breeder.

\section{Materials AND Methods}

A collection of 800 barley varieties was assembled from barley-growing areas of the world. Commercial varieties, both new and old, and many ecotypes from natural habitats were included. A range of varieties possessing various nutant marker genes and abnormal morphological and physiological features completed the collection. This representative assembly of genotypes contained approximately equal proportions of the two-row and six-row varieties.

Although many characters of the whole collection were examined, only the grain yield data of a random subsample of 277 varieties is reported in this study. These varieties were grown in a three-replicate, randomized block layout at Minlaton and Clinton on Yorke Penirisula in 1958, 1959, and 1960, and at the Waite Institute in 1960. All these centres are in the South Australian cereal belt. A brief summary of the soil type and effective rainfall for each of the test sites and seasons is given in Table 1.

The experimental plots, each of three rows, $7 \mathrm{in.}$ apart and $10 \mathrm{ft}$ long, were sown 14 in. apart with pathways 3 fit wide between blocks of plots. The experiments were sown with a magazine-loaded semi-automatic seed drill (Finlay 1963). 
A statistical technique was developed to compare the performance of a set of varieties grown at several centres for several seas: ns. For each variety a linear regres. sion of individual yield on the mean yield of all varieties for each site in each season was computed. (It was subsequently found that Yates and Cochran (1938) had described a similar method for analysing groups of experiments. The regression proceduse used in the present study, however, is developed a great deal further thar that of Yates and Cochran and is used to describe the adaptation response of individual varieties to the range of environments in which they were grown and to assess a population of varieties for adaptation and yield performance.) The mean yield of all

TABLE 1

SOME SITE ANU SEASONAL DIFFERENCES AT THE LOCATION OF THE YIELD EXPERIMENTS

\begin{tabular}{|c|c|c|c|}
\hline \multirow{2}{*}{ Difference } & \multicolumn{3}{|c|}{ Site of Experiments } \\
\hline & Clinton & Minlaton & Waite Institute \\
\hline $\begin{array}{c}\text { Soil type } \\
.\end{array}$ & Loamy' mallee & $\begin{array}{l}\text { Shallow sand over- } \\
\text { laying limestone }\end{array}$ & Red-brown earth \\
\hline $\begin{array}{l}\text { Nermal planting } \\
\text { time }\end{array}$ & Mid May & Mid July & Mid June \\
\hline $\begin{array}{c}\text { Rainfall (in.):* } \\
1958 \\
1959 \\
1960\end{array}$ & $\begin{array}{r}14 \cdot 14 \\
4 \cdot 82 \\
14 \cdot 25\end{array}$ & $\begin{array}{r}14 \cdot 27 \\
6 \cdot 67 \\
15 \cdot 44\end{array}$ & $\frac{-}{24 \cdot 62}$ \\
\hline
\end{tabular}

*April to November inclu: Ive.

277 varieties at each site and for each season (hereafter referred to as "site means") provides a numerical grading of sites and seasons and, it is suggested, a useful evaluation of the environment. For example, as shown in Figure 2, the mean yield of all varieties at Clinton in 1959 (C59) was very low, which indicated a low-yielding environment; on the other hand Clinton in 1958 was a high-yielding environment, as shown by the very high site mean (C58). In this way the average yield of a large group of varifities is used to describe a complex natural environment without the complexities of defining or analysing the interacting edaphic and seasonal factors.

In the calculations of means and regressions referred to above and elsewhere in this paper, the basic yields were measured on a logarithmic scale, since it was found that by this means a high degree of linearity was induced in the regressions of individual yields on the site means. Use of a logarithmic scale also induced a reasonable degree of homogeneity of experimental error. It should be noted that means of yields on a logarithmic scale correspond to geometric means on the natural scale, instead of the more usual arithmetic means. This distinction is not of any cunsequence in the 
preliminary broad study of a collection of varieties as described in this paper, $b$ would ultimately have to be taken into account in a more detailed examination of $t$ performance of individual varieties.

An electronic computer was used for most of the statistical analysis.

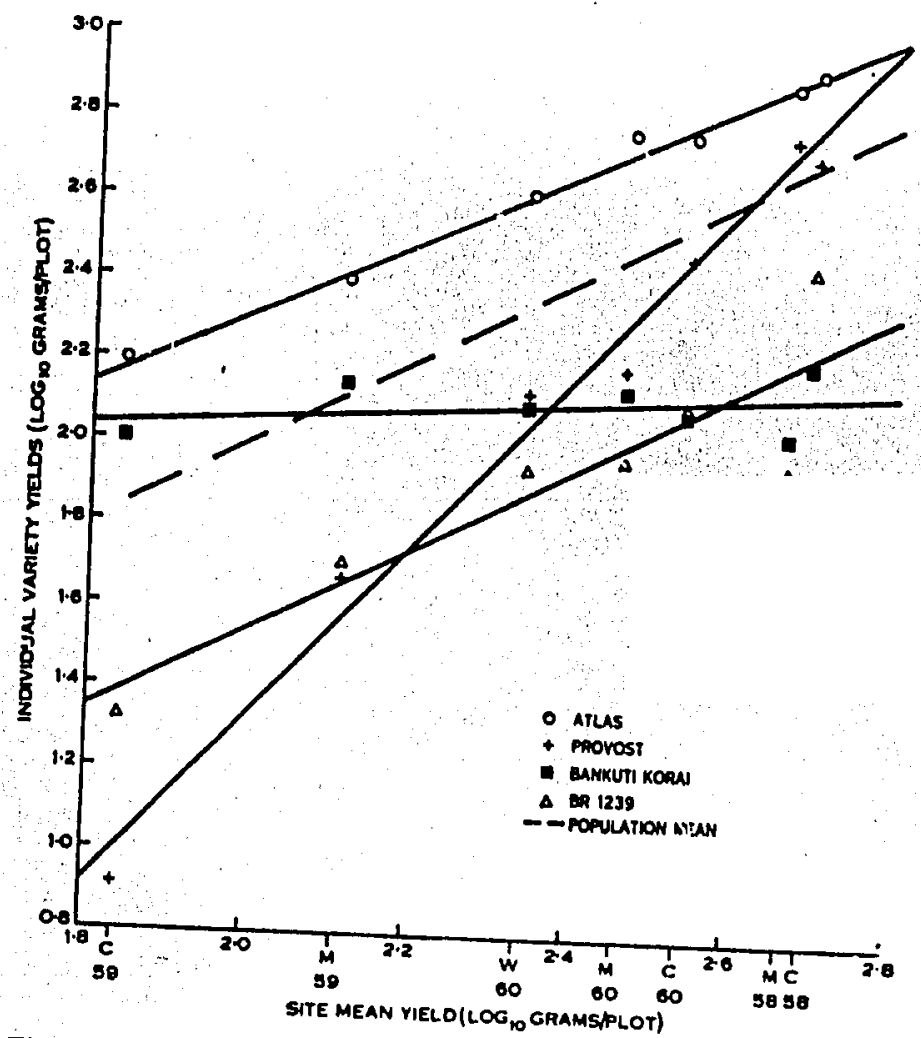

Fig. 2.-Regreasion lines, showing the relationship of individual yields of four varieties and population mean of 277 varieties of barley grown at different sites and seasons. C, Clinton; $M$, Minlaton; W, Waite Institute. 58, 59, 60 represent 1958, 1959, 1960.

\section{II!. Results}

The population mean and the regression lines for four of the 277 varieties are shown in Figure 2 to illustrate different types of varietal response to the range of environments. Because the individual variety yields are plotted against the mean of all the variety yields, the population mean has a regression coefficient of 1.0 .

Yarietic's characterized by regression coefficients of the order of 1.0 have average stability over all environments. For example, the variety Atlas shows average stability, with a linear regression coefficient $(b)$ of 0.90 . It produced above-average yields in all seasons at all sites, which indicated that it has general adaptability. On the other hand, BR 12.39 also has a regression coefficient approximating $1.0(b=1 \cdot 05)$ but consistentiy produced below-average yields. It is poorly adapted to all environments. 
Provost is typical of varieties which are very sensitive to changes in the environment (below average stability): small changes in the environment produce large changes in yield. This variety yields very little grain in a low-yielding environment, but as the environment improves, thus favouring higher yields, Provost's yield increases at a rate well above the average for the group. Under the inost favcurable conditions it becomes one of the highest-yielding varieties. Provost can therefore be described as being specifically adapted to high-yiclding environments, and is characterized by a regression coefficient significantly greater than $1 \cdot 0(b=2 \cdot 13)$.

Bankuti Korai exhibits the opposite type of adaptation, with very little change in yield despite large changes in the environment (above average stability). This variety produces above-average yield in low-yielding environments, but being insensitive to environmental change it yields reiatively little grain in a high-yielding environment. Bankuti Korai, with a regression coefficient significantly less than $1 \cdot 0(b=0 \cdot 14)$, therefore typifies varieties specifically adapted to low-yielding environments.

TAB!E 2

MEAN SQUARES FROM ANALYSI3 OF VARIANCE OF THE MELOS (ON LOG 10 SCALE) OF 277 BARLEY VARJETES OROWN IN SEVEN NATURAL ENVIRONMENTS

\begin{tabular}{l|r|r}
\hline \multicolumn{1}{c|}{ Source } & D.F. & Mean Square \\
Genotypes & 276 & $0.5618^{* *}$ \\
Environments & 6 & $125.5803^{* * *}$ \\
Genotypes $x$ environiments & 1656 & $0.0616^{* * *}$ \\
$\quad$ Regressions & 276 & $0.2227^{* *}$ \\
$\quad$ Deviations from regressions & 1380 & $0.0294^{* *}$ \\
Replicates within environments & 14 & $0.5385^{* *}$ \\
Residual & 3864 & 0.0186 \\
& & \\
\hline
\end{tabular}

$* * P<0.01$.

The regression technique used in this study is particularly effective in emphasizing the actual trend of varietal yield responses to a range of natural environments. From the analysis of variance set out in Table 2 it can be shown that $79 \%$ of the genotype $x$ environment variance component is attributable to the linear regressions. A less extreme range of environments would of course reduce the proportion of the variance component for genotype $\times$ environment interaction explained by variation in the individual regression coefficients.

The residual genotype $\times$ environment variance $(0 \cdot 0294)$, it may be noted, is little more than $50 \%$ higher than experimental variance. The magnitude of the corresponding variance cornponent implies, with reference to the natural scale of yield, that deviations from the regressions of yield on environment have a coefficient of variation (excluding purcly experimental variability) of approximately $14 \%$.

The two important indices in this type of analysis are the regression coefficient and the variety mean yield over all environments. To summarize, regression coefficients approximating to 1.0 indicate average stability. When this is associated with 


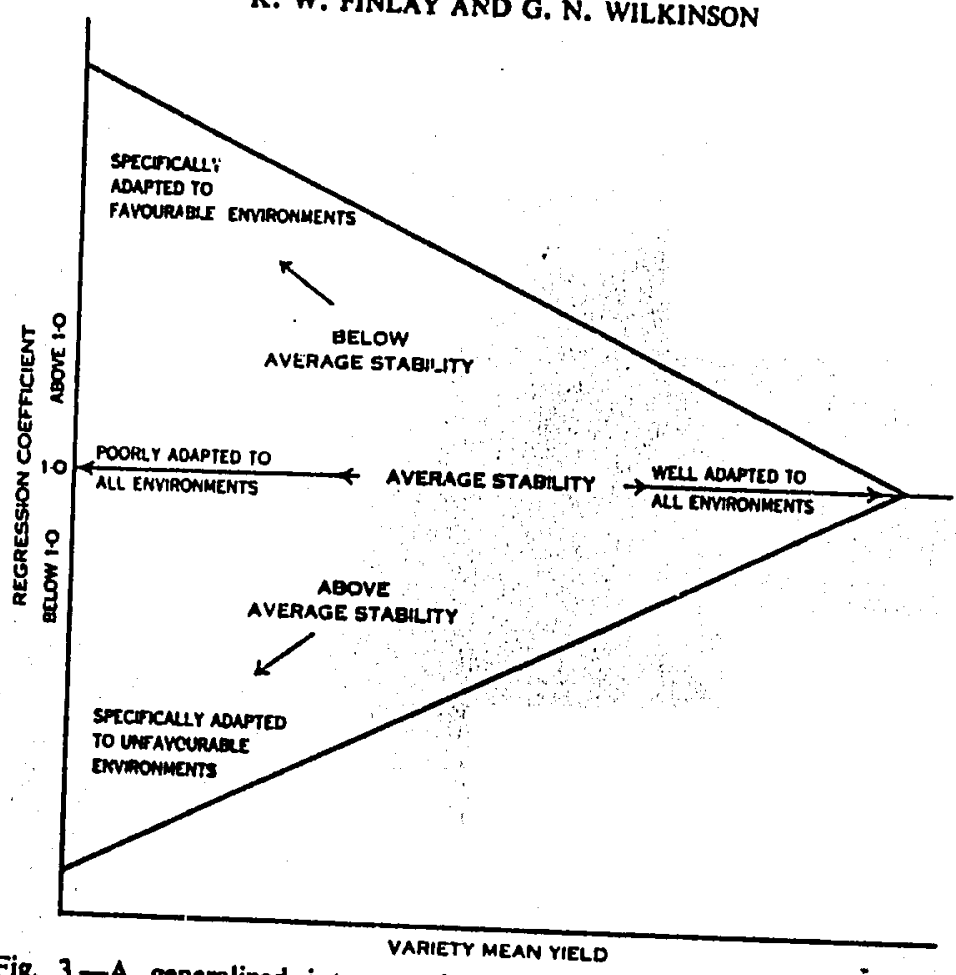

Fig. 3.-A generalized interpretation of the variety population pattern obtained when variety regression coefficients are plotted against variety mean

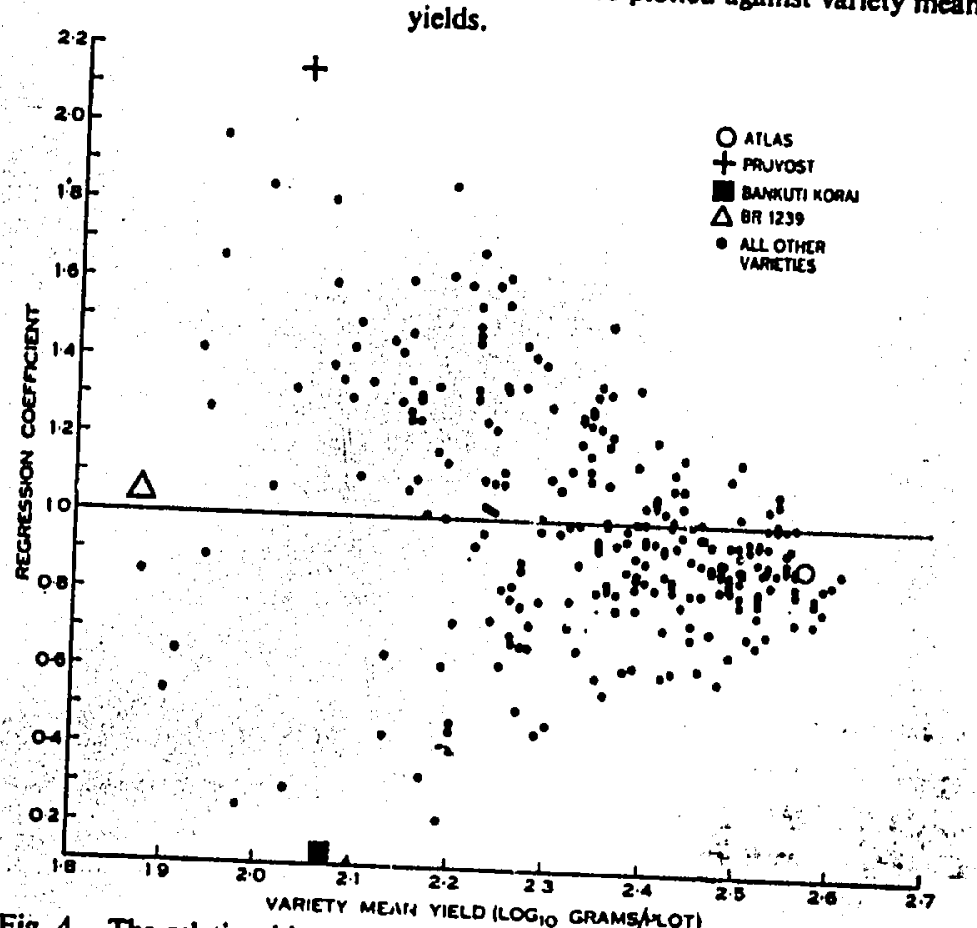

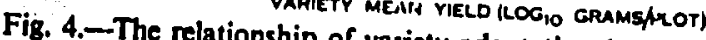
variety mean yield for 277 barley varieties. 
high mean yield, varieties have general adaptability; when associated with low mean yield, varieties are pocrly adapted to all the environments. Regression values increasing above 1.0 describe varieties with increasing sensitivity to environmental change (below average stability), and greater specificity of adaptability to high-yielding environments. Regression coefficients decreasing below 1.0 provide a measure of greater resistance to environmental change (above average stability), and therefore increasing specifieity of adaptability to low-yielding environments.

The second index, the variety mean yield over all environments, provides a comparative measure of performance of the individual varieties. For example, the mean yield over all environments of Atlas is greater than those of Provost or Bankuti Korai which in turn are greater than the mean yield of BR 1239 .

A further analysis of the behaviour of all the varieties tested in this programme can be achieved by plotting these two indices together as coordinates in a twodimensional scatter diagram. This permits a still wider interpretation of the data (Figs. 3, 4).

Figure 3 provides a generalized version of the interpretation which can be applied to the data plotied in Figure 4, where each variety is represented by a single point. It is the position of this point which indicates the type of adaptability (regression coefficient) and the average yield performance of each variety. The varieties Atlas, Provost, Bankuti Korai, and BR 1239 have been assigned individual symbols (as for Fig. 2) to allow direct comparisons between Figures 2 and 4. All other varieties are uniformly marked to indicate the population pattern. Figure 4 consolidates the information given in Figure 2, and has the advantage that a large collection of varieties can easily be depicted.

The distribution of varieties with regard to mean yield will depend on the particular sample of seasons and sites used for the estimation. If the seasons and sites have provided predominantly high-yielding environments, then the varieties with high regression coefficients will produce the highest mean yields, showing that varieties specifically adapted to high-yielding environments have been favoured. In the present study, the range of seasons and sites favoured the generaily adapted varieties, with only a slight bias towards varieties specifically adapted to low-yieldirig environments.

Varieties originating in, or bred specifically for, particular geographic areas of the world tend to have a degree of genetic similarity. In Figure 5, lines are drawn around all the varieties from particular geographic areas. The shape of the enclosed area has no significance per se, but the position of the area shows the type of adaptation of the varietal group.

To avoid confusion, several groups of areas have been illustrated separately and points for the individual varieties have been left out, except in the top left diagram, where Figure 4 is repeated with lines representing the regression coefficient 1.0 (average stability) and the population mean yield as markers to simplify comparisons. A few varieties have been omitted for one of the following reasons: ( $($.$) the origin of the$ variety is unknown; $(b)$ there are too few varieties from a particular geographic region to be representative, e.g. only three varieties are from China; (c) the variety is a genetic or morphological oddity used for experimental purposes and not necessarily adapted 

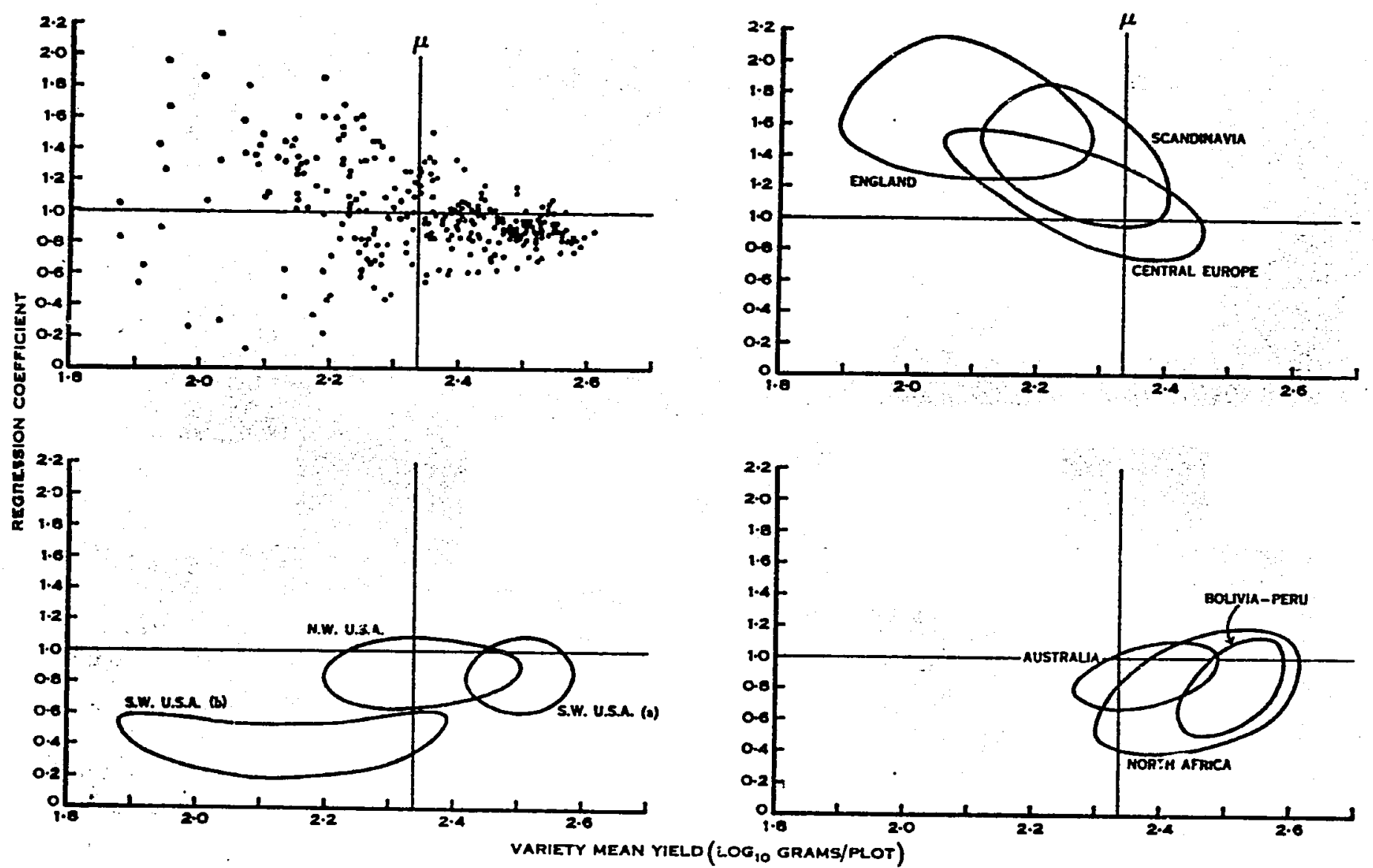

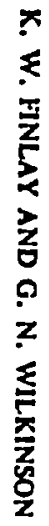

Fig. 5. - The relationship of geographic area of origin and type of variety adaptation indicated by position relative to the marker lines regression coefficient $1 \cdot 0$ (general adaptability) and population mean yield $(\mu)$. 
to the region in which it was produced. All other varieties are included in the enclosed areas.

Figure 5 shows that the English and, to a lesser degree, the Scandinavian varieties are specifically adapted to high-yielding environments. This is to be expected, because they were bred for the relatively consistent, high moisture, and high fertility conditions prevailing in England, Denmark, and Sweden. In southern Australia, however, most of these varieties rarely have the opportunity to show their full potential, and because of their extreme sensitivity to environmental change, in particular to dry seasons or those which cut cff early, they often produce very low yields. This is reflected in their low mean yields over all sites and seasons.

Many of the centra! European varieties have average stability, although as a group their mean yield is only average. It is of interest that many varieties of this group show a pattern of adaptability and mean yield similar to that of Australian varieties and those from the north-west of the United States.

Varieties from North Africa, Bolivia, Peru, and the south-west of the United States $(a)$ also have average stability, here associated with above-average mean yields, which indicated good general adaptability. Most varieties from these geographic regions showed outstanding performancs, producing above-average yields in all sites and seasons; they far oulyielded the Australian varieties. The mean yields, o'er all sites and seasons, of the highest-yielding two-row and six-row varieties were $35 \%$ ard $60 \%$ respectively, higher than that of the Australian commercial variety Prior.

In Figure 5, the group of varicties from the south-west of the United States (b) is of interest, because they are all introduced or derived from varieties such as California Mariout which, according to Aberg and Wiebe (1946), originated in Egypt, where it is grown by Arab farmers along the Mediterranean without irrigation and with a rainfall of about 8 in. These varieties are all specifically adapted to lowyielding environments.

\section{Discussion}

\section{(a) Genotype Adaptation}

The lack of a quantitative measure of complex natural environments, more than any other single factor, has held up the study and exploitation of adaptation in plant introduction and breeding programmes. The use in the present study of an average performance value (yield) of a large group of varieties has provided an abstract measure of the environment. This value (site mean) provides a useful method for quantitatively grading sites and seasons (Fig. 2).

These site means (Fig. 2) illustrate the importance of seasonal variability as a principal factor of the environmen $\hat{i}$ in the test region. The highest and lowest site means were obtained on the same farm at Clinton in 1958 and 1959 respectively. Differences in edaphic factors between the three sites appear to have relatively little significance in the environment when compared to seasonal fluctuations. Had these experiments been carried out only at Clinton for 3 years, substantially the same result would have been obtained. 
Plant breeders are inclined to ignore the results obtained in low-yieldin! environments (e.g. drought years), on the basis that the yields are too low and are therefore not very useful for sorting out the differences between selections. This is a serious error, because high-yiclding selections under favourable conditions may show relatively greater failure under adverse conditions. The practice of ignoring "crop failures" will bias the selection towards types specifically adapted to high-yielding environments, and will pass over those with general adaptability.

Many introduced barley varieties with good general adaptability produce much higher mean yields than the Australian varieties. Unfortunately their malting quality is low, but to the breeder they indicate the source and the potential for improvement of yield. Malting quality is concentrated primarily in the varieties from England, Scandinavia, and central Europe. Selection programmes resulting from simple and multiple crosses between varieties from these regions and those from regions producing varieties with good general adaptability are in progress.

\section{(b) Phenotypic Stability}

The simple linear regressions used to describe various types of variety adaptability to a range of environments can also be used as a quantitative measure of phenotypic stability. Varieties such as Bankuti Korai with a very low regression coefficient $(b=0 \cdot 14)$ show a high degree of phenotypic stability. The yields in each environment are almost the same. Absolute phenotypic stability would be expressed by $b=0 \cdot 0$. Figure 2 shows the advantage in terms of survival of phenotypically stable Bankuti Korai: in poor environments, this varicty maintains its yield and, relative to the other varieties, yields mure as the environments become yet poorer. Provost, a phenotypically unstable variety $(b=2 \cdot 13)$ fails to produce seed at all in
very poor environments.

One of the most interesting features of this study is that the variability (between varieties) in phenotypic stability (regression coefficient) is inversely proportional to the mean yield, as indicated by the triangular configuration of points in Figure 4 . The varieties with general adaptability (highest mean yiclds over all environments) all possess slightly above-average phenotypic stability $(b=$ approx. $0 \cdot 80)$. The phenotypic stability of varieties with low mean yields ranges from $b=0 \cdot 14$ to $b=2 \cdot 13$.

The ideal variety having general adaptability is the one with maximum yield potential in the most favourable environment, and maximum phenotypic stability. The varieties having general adaptability in the present study have fallen far short of this ideal. The varieties with the high phenotypic stability all have low mean yields. They are so stable, in fact, that they are unable to exploit high-yiclding environments. On the other hand, varieties can be too sensitive to environmental change, as is shown by the low mean yields of the varieties with high regression coefficients. The generally adapted varieties balance between these extremes, the actual point of balance depending on the particular genotype and range of environments. A breeding programme designed to produce a variety with still higher mean yield over ail environments will almost certainly fall short of the ideal, but as yet there is no way of 
predicting what sort of compromise will be reached between yield potential and phenotypic stability in determining its high average performance.

\section{(c) Plant Characters and Adaptation}

A number of morphological and physiological characteristics were measured for the varieties tested. The one of most significance is maturity, based on dates of heading and harvest. As would be expected, the very early varieties tend to be specifically adapted to low-yielding environments (although not all varieties specifically adapted to low-yielding environments are early-maturing). Similarly the late varieties tend to be specifically adapted to the high-yielding environments. It is particularly interesting that a very wide range of maturity types, from early to late, are represented in the generally adapted group having very high mean yields.

Although more detailed study is required, this work has particular significance in plant introduction and breeding programmes. There has been a very strong tendency in southern Australia to concentrate on the selection of varieties with early, or earlymid-seascn maturity. In plant introduction programmes large numbers of varieties have been discarded in early testing, almost exclusively on the basis of maturity. Much potentially valuable material may have been lost in this way.

Groups of varieties adapted to any specific environment have been found to have many morphological and physiological factors common to all varieties. However, in the generally adapted group, no factors common to a high proportion of the group have been found. 'The varieties from this group with good general adaptability, capable of producing very high yields of grain under conditions of widely fluctuating seasonal ennironments, have many different growth forms and physiology. This would indicate that although it may be possible eventually to define the characteristics for the ideal plants adapted to specific environments, it could be much more difficult to define all the possible combinations of a range of characteristics necessary to provide good general adaptability to a widely fluctuating set of seasons. This is of particular importance when crop workers are seeking to define the form of the ideal crop plants. Much of this work is being done with a very limited range of genotypes which have been rather arbitrarily selected. Specific findings from such studies, if widely applied as an important criterion of selection in plant introduction and br:eding programmes, could lead to the discarding of valuable material and reduction of the rate of plant improvement.

The study of an international variety collection, as described in this paper, provides not only fundamental information but also a useful basis for the selection of - the material for basic study, or parents for plant improvement programmes.

\section{ACKNOWLEDGMENTS}

The authors wish sincerely to thank Mr. K. Cellier, Division of Mathematical Statistics, C.S.I.R.O., and Professor E. E. Remmenga of Colorado State University for their assistance with the statistical analysis and computer programming; and Messrs. A. V. Lehmann, T. Annells, and J. Burton for excellent technics! assistance. 
For funds to carry out the extensive field programme, grateful acknowledgment is made to the Technical al.d Advisory Committees of the Barley Improvement Trust Fund.

\section{ReFERENCES}

Ázero, E., and WIEBE, G. A. (1946).-Tech. Bull. U.S. Dep. Agric. No. 907.

Dobzhansky, Th., and LeVEne, H. (1955a).-Genetics 40: 797-808.

Dobzhansky, Th., Pavlovsky, O., Spassky, B., and Spassky, N. (1955b).-Genetics 40: 781-ð6.

Finlay, K. W. (1963).-J. Agric. Engng. Res. 8: 41-7.

Frankel, O. H. (1958).-J. Aust. Inst. Agric. Sci. 24: 112-23.

Gruffino, B., and Lanoridge, J. (1951).-Symp. Statist. Geneties and Plant Breeding, Raleigh, N. Carolina, 1961 (in press).

HORNER, T. W., and FreY, K. J. (1957).-Agron. J. 49: 31'j-15.

Imater, F. R., Hiyes, H. K., and Powers, Le Roy (1934).-Agron. J. 26: 403-19.

LERNeR, I. M. (1954).- "Genetic Homieostasis." (Oliver \& Boyd: London.)

LEWL, D. (1954). - Fieredity 8: 333-56.

Lewis, D. (1955).-Proc. Roy. Soc. B 144: 178-85.

SALMON, S. C. (1951).-Agror. J. 43: 562-70.

SANDLSON, A., and BartLetT, B. O. (1958).-J. Nat. Inst. Agric. Bot, 8: :351-7.

W'nuLAMs, W. (1960).-Genetics 45: 1457-65.

YATES, F., and COCHRAN, W. G. (1938). J. Agric. Scl. 28: 556-80. 